\title{
Effects of repeated ochratoxin exposure on renal cells in vitro
}

\author{
A.H. Heussner, E. O'Brien, D.R. Dietrich * \\ Environmental Toxicology, University of Konstanz, P.O. Box X-918, 78457 Konstanz, Germany
}

\begin{abstract}
In the present study an in vitro model of subchronic repeated exposure to OTA and OTB was employed to generate ochratoxinderived subpopulations of human and porcine proximal tubular cells (HKC, IHKE, PKC, LLC-PK1). These cell subpopulations were subsequently used to investigate effects on cell proliferation rates, expression of marker proteins (cytokeratins, vimentin) and the acute cytotoxicity of OTA and OTB (MTT reduction, neutral red uptake, cell number). The hypothesis was tested whether repeated exposure at moderate concentrations of these toxins could provide for a reduced sensitivity of selected cell subpopulations to subsequent toxin exposure. Despite the observed increased cell population doubling times and the reduced sensitivity toward OTA and OTB exposure of some cell types, with the exception of the primary human epithelial cells, no overt changes in the expression of cytokeratin and vimentin could be determined. The presented data, however suggest that repeated exposure of renal epithelial cells to ochratoxins A or B will provide for a subpopulation of cells with reduced ochratoxin-sensitivity and alterations in growth characteristics.
\end{abstract}

Keywords: Ochratoxins; Renal cells; Repeated exposure; Nephropathy

\section{Introduction}

Ochratoxins are secondary metabolites of certain ubiquitous Aspergillus and Penicillium species and are known contaminants of human food and animal feed often arising due to sub-optimal storage conditions (Speijers and van Egmond, 1993; Studer-Rohr, 1995). Chronic dietary exposure to ochratoxin A (OTA) has long been associated with the renal disease, known as Balkan Endemic Nephropathy (BEN) and with an increased incidence of urothelial tumors in humans. Presently, the hypothesis of BEN being an environmentally acquired disease with ochratoxins being one of the principal potential etiological factors (others include the aristolochic acid or the Pliocene lignite hypotheses), is widely accepted (Stefanovic et al., 2006; Pfohl-Leszkowicz et al., 2002; Tatu et al., 1998). The pathological characteristics of BEN include diffuse cortical fibrosis and degenerative changes of the renal epithelium. Not only humans can be

\footnotetext{
* Corresponding author. Tel.: +49 7531 883518; fax: +49 7531883170 . E-mail address: daniel.dietrich@uni-konstanz.de (D.R. Dietrich).
}

affected by exposure to ochratoxins. Indeed many similarities, including atrophic proximal tubules and fibrotic tissue, have been reported between the later stages of BEN and mycotoxin-induced porcine nephropathy (MPN) (Stoev, 1998). Rásony and co-workers reported a similar OTAinduced loss of proximal tubular cells, accompanied with increased regenerative processes, in rats following oral OTA exposure (Rásonyi et al., 1999).

The mechanism of OTA-mediated cell death remains a question of debate (for review see Dekant et al., 2005; O'Brien and Dietrich, 2005), but it seems that in all species investigated to date, including humans, the kidney attempts to balance cell loss with regenerative processes and the question of whether this loss of tissue can be replaced via proliferation of epithelial or fibroblastic neighboring cells remains unanswered. Regeneration is most likely driven by a combination of migration and/or proliferation and subsequent cell differentiation after sublethal injury. Consequently, this could lead to the appearance of an altered cell type, exhibiting neither functional nor morphological characteristics of the original cell type and as such, would be consistent with the genesis of fibrosis and of renal tumors. 
A complete outline of renal regeneration processes following acute injury is beyond the scope and intention of this research manuscript, however a good overview of these mechanisms is given by Nony and Schnellmann (2003).

Previous in vitro observations have demonstrated that even after acute exposure to highly toxic concentrations of ochratoxins $(\geqslant 10 \mu \mathrm{M})$, approximately $10 \%$ of cells survive and can recommence proliferation (O'Brien et al., 2001). These cells have also been described to display a more fibroblast-like rather than epithelial appearance (Heussner et al., 2002). The latter findings, coupled with the observations that fibroblasts are less susceptible to ochratoxin-mediated toxicity (Grotegut et al., 2001; O'Brien et al., 2001), gave rise to the hypothesis that repeated exposure to ochratoxins alters normal renal epithelial cells, possibly converting them to a more fibroblast-like nature, thus, providing the rudiments for renal fibrosis (van Kooten et al., 2001). Support for this hypothesis was presented by the recent publication of Sauvant et al. (2005), who described an increase in collagen synthesis in OK cells and primary human renal proximal tubular epithelial cells (RPTEC) following exposure to OTA. All of these observations are mostly descriptive in nature and need to be further characterized. If indeed changes toward a more resistant cell type are involved in the regenerative processes following OTA insult, these should be reflected by alterations in parameters such as morphology, growth rate, protein expression and susceptibility to acutely cytotoxic concentrations of ochratoxins. It was therefore the aim of this study to determine whether OTA and/or OTB treatment of renal proximal tubular cells will result in the latter alteration of parameters.

For this, a model of repeated ochratoxin-induced cell loss with alternating regenerative periods was employed in this study in order to mimic the dietary situation of (sub)chronic interval exposure in humans and animals. Using this approach, various renal cell subpopulations of continuous renal cell lines and primary cells of porcine and human origin were generated and characterized with regard to morphology, growth rate, protein expression and susceptibility to acutely cytotoxic concentrations of ochratoxins.

\section{Material and methods}

\subsection{Mycotoxins and reagents}

Highly purified ochratoxin A and B ( $>98 \%$ purity, benzene free) were kindly provided by M.E. Stack, US FDA, Washington, DC. Sterile ochratoxin stock solutions were prepared in $0.1 \mathrm{M} \mathrm{NaHCO}_{3}$ and freshly diluted (dilution factor $=40$ ) in culture medium immediately before exposure. Media, FBS and other cell culture chemicals were purchased from PAA Laboratories $\mathrm{GmbH}$, Cölbe, Germany. MEM/D-Val medium was purchased from Life Technologies, Karlsruhe, Germany. Unless otherwise sta- ted, all other chemicals were purchased from SigmaAldrich GmbH, Seelze, Germany.

\subsection{Biopsy material and animal tissue}

Human renal biopsy material (male patients) was obtained from a local hospital (Klinikum Konstanz) in collaboration with the Department of Urology, Prof. Dr. R. Thiel, subsequent to informed patient consent. Tissue samples as well as patient data were handled in compliance with the stipulations put forth by the ethics committee of the University of Konstanz and in fulfillment of German law and the Declaration of Helsinki (1964) pertaining to personal data protection and handling of human biopsy material.

Whole kidneys from freshly-killed male improved German hybrid pigs were obtained from a local slaughterhouse.

\subsection{Cell cultures}

Primary male human kidney cells $(\mathrm{HKCm})$ and primary male porcine kidney cells (PKCm) were prepared by standard collagenase digestion from renal cortices and cultured as previously described in detail (Dietrich et al., 2001). Briefly, minced renal cortices were incubated with buffered collagenase type $1(1 \mathrm{mg} / \mathrm{ml})$ at $37^{\circ} \mathrm{C}$ for 30 min with gentle stirring and subsequently filtered through gauzes (200 and $40 \mu \mathrm{m})$. Cultures were initiated in Primaria tissue culture flasks (Becton Dickinson $\mathrm{GmbH}$, Heidelberg, Germany) using MEM D-Val medium supplemented with $10 \%$ FBS and antibiotics $(100,000$ units/L penicillin, $100 \mathrm{mg} / \mathrm{L}$ streptomycin) to prevent fibroblast growth. Once small cell colonies were established, MEM D-Val was replaced by DMEM/F12 medium, supplemented with FBS and antibiotics.

LLC-PK1 cells were obtained from the European Collection of Cell Cultures, Salisbury, UK (ECACC No. 86121112) and IHKE cells were kindly provided by S. Mollerup, National Institute of Occupational Health (STAMI), Oslo, Norway. Both cell lines were cultured in DMEM, supplemented with $10 \%$ FBS and antibiotics as for primary cells.

All four cell types were cultured under standard conditions $\left(37^{\circ} \mathrm{C}, 5 \% \mathrm{CO}_{2}\right)$.

\subsection{Generation of ochratoxin cell subpopulations (study part A)}

IHKE, LLC-PK1, HKCm and PKCm of passage number $4,8,1$ and 1 , respectively, were seeded at a density of $1 \times 10^{4}$ cells $/ \mathrm{cm}^{2}$ into $182 \mathrm{~cm}^{2}$ culture flasks in their appropriate medium. Medium was replaced every $48 \mathrm{~h}$. As indicated by preliminary experiments, after reaching $80-90 \%$ confluence, cells were exposed to nominal concentrations of 20 and $50 \mu \mathrm{M}$ OTA or OTB until approximately $90 \%$ of the cells had died (depending on cell type, approximately 
72-96 h, ochratoxins were replenished with each medium change). These concentrations were chosen on the basis of earlier cytotoxicity findings with $20 \mu \mathrm{M}$ of either, OTA and $\mathrm{OTB}$, representing a moderately toxic concentration $\left(\sim \mathrm{EC}_{50}\right)$ and $50 \mu \mathrm{M}$ being highly toxic $\left(\geqslant \mathrm{EC}_{80}\right)$, depending on endpoint and exposure duration (Dietrich et al., 2001).

The ochratoxin-containing medium was then discarded, the cells were washed once with PBS $(136.9 \mathrm{mM} \mathrm{NaCl}$, $2.7 \mathrm{mM} \mathrm{KCl}, 8.1 \mathrm{mM} \mathrm{Na} \mathrm{HPO}_{4}, 1.5 \mathrm{mM} \mathrm{KH_{2 }} \mathrm{PO}_{4}, \mathrm{pH}$ $7.4, \leqslant 300 \mathrm{mOsM}$ ) and further cultured with fresh medium until approximately $90 \%$ confluence was attained. This regimen of exposure and recovery was repeated a further two times to generate subpopulations of ochratoxin-exposed cells. In parallel, vehicle control cultures were exposed to a final concentration of $2.5 \mathrm{mM} \mathrm{NaHCO} 3$ and passaged at approximately $90 \%$ confluence using trypsin/EDTA in order to provide comparable control cells. The resulting cell cultures were designated subpopulations after the third exposure interval or passage and used for further experimentation (see Table 1 for overview of subpopulations and Fig. 2 for repeated exposure time schedule).

\subsection{Determination of growth characteristics (study part B)}

For the determination of growth characteristics of all subpopulations, growth curves were established using a Coulter counter (Coulter Z1, Beckman Coulter GmbH, Krefeld, Germany) as previously described (Dietrich et al., 2001).

\subsection{Immunodetection of cytokeratins and vimentin (study part B)}

Confluent cell subcultures were harvested using trypsin/ EDTA and intermediate filaments were isolated according to standard procedures (Eckert and Kartenbeck, 1997). Proteins were separated by $12 \%$ SDS-PAGE and electroblotted onto nitrocellulose membranes. Immunostaining was performed using mouse anti-cytokeratin (clone AE1/ AE3, Biomeda Corp., Hayward, CA, USA), mouse antivimentin (clone V9, Biomeda Corp., Hayward, CA, USA) and HRP-conjugated rabbit anti-mouse IgG (DakoCytomation GmbH, Hamburg, Germany, cat. no. P0260) with subsequent chemiluminescent (ECL, Amersham Biosciences, Uppsala, Sweden) and colorimetric (DAB sub-

Table 1

Overview of cell culture subpopulations

\begin{tabular}{ll}
\hline Subpopulation no. & Repeated $(3 \times)$ exposure to \\
\hline Untreated & Vehicle \\
lowOTA & $20 \mu \mathrm{M}$ OTA \\
highOTA & $50 \mu \mathrm{M}$ OTA \\
lowOTB & $20 \mu \mathrm{M}$ OTB \\
highOTB & $50 \mu \mathrm{M}$ OTB \\
\hline
\end{tabular}

Vehicle $=2.5 \mathrm{mM} \mathrm{NaHCO}$. strate kit, Roche Diagnostics GmbH, Mannheim, Germany, cat. no. 1718096) detection according to the manufacturers' instructions.

\subsection{Acute challenge experiments with ochratoxins (study part C)}

Cell culture subpopulations were seeded at $1 \times 10^{4}$ cells/ $\mathrm{cm}^{2}$ in serum replete medium, on normal tissue culture plastics for experiments as described previously (Dietrich et al., 2001). Exposure to OTA or OTB, each at nominal concentrations of $0.1,1,5,10,15,20$ and $50 \mu \mathrm{M}$ or to vehicle $\left(2.5 \mathrm{mM} \mathrm{NaHCO}_{3}\right)$ for $24,48,72$ and $96 \mathrm{~h}$ began $24 \mathrm{~h}$ after seeding.

MTT reduction (MTT), neutral red uptake (NR) and cell number were assessed as previously described (Dietrich et al., 2001).

\subsection{Calculations and statistical data analysis}

Cytotoxicity data are presented as integrated best-fit $\mathrm{IC}_{50}(24-96 \mathrm{~h})$ values ( $50 \%$ inhibitory concentrations) from non-linear regression $\pm 95 \%$ confidence intervals based on asymptotic standard errors. These data were generated using GraphPad Prism version 4.0 for Windows and Excel software (Microsoft Excel 2000) from the mean percentage inhibition for each endpoint at each test substance concentration from at least three independent experiments carried out in duplicate. Values were calculated as the difference between the area under the control curve and the area under the curve for each substance concentration, integrated over 24, 48, 72 and $96 \mathrm{~h}$, using the following equations:

$A=\frac{N_{1}}{2} \cdot t_{1}+\frac{N_{1}+N_{2}}{2} \cdot\left(t_{2}-t_{1}\right)+\frac{N_{3}+N_{4}}{2} \cdot\left(t_{4}-t_{3}\right)$

$I_{A}=\frac{A_{\mathrm{c}}-A_{\mathrm{t}}}{A_{\mathrm{c}}} \cdot 100$

with $A$, area under the curve; $N_{n}$, endpoint value (\% control MTT reduction, \% control NR uptake or $\%$ control cell number) at timepoint $n ; t_{n}$, timepoint $n(24,48,72$ or $96 \mathrm{~h}) ; I_{A}, \%$ inhibition; $A_{\mathrm{c}}$, area under the control curve and $A_{\mathrm{t}}$, area under the toxin curve.

Only intrapolated $\mathrm{IC}_{50}$ values are reported, extrapolated data, where calculated values were higher than the tested concentration range, were presented only as " $\geqslant$ " or " $>$ " maximum tested concentration in order to avoid speculation with mathematically correct, but biologically irrelevant data.

Subpopulation growth characterization data were calculated as arithmetic means \pm SEM from three independent experiments carried out in duplicate.

Significance of differences compared to control cells or between subpopulations was tested using a one-way ANOVA followed by Tukey's multiple comparison test. 


\section{Results}

\subsection{Generation of cell subpopulations (study part A)}

The described study design (Fig. 1, part A) of repeated exposure of four different renal cells to ochratoxins resulted in five subpopulations for each cell type (Table 1). Routine microscopy of cell cultures (with approximation of level of confluence) showed that during the exposure intervals cells became less sensitive to ochratoxins as illustrated for IHKE cells in Fig. 2. This loss of sensitivity was timedependent and more prominent for cell lines than for primary cells and was further characterized in subsequent experiments with the individual subpopulations as described in detail below.

Overt morphological transformations were not evident in the subpopulations generated by repeated exposure to ochratoxins.

\subsection{Growth characteristics of cell subpopulations (study part B)}

The results of growth characterization are summarized in Fig. 3. With the exception of the lowOTA-subpopulation (see Table 1), which was completely unaffected, HKCm subpopulations displayed an increased population doubling time (Fig. 3A), i.e. from $31.0 \pm 0.5$ (untreated) to $43.0 \pm 3.4 \mathrm{~h}$ (highOTA) (see Table 1). Similarly, highOTA selection provided for overtly increased doubling time in LLC-PK1.

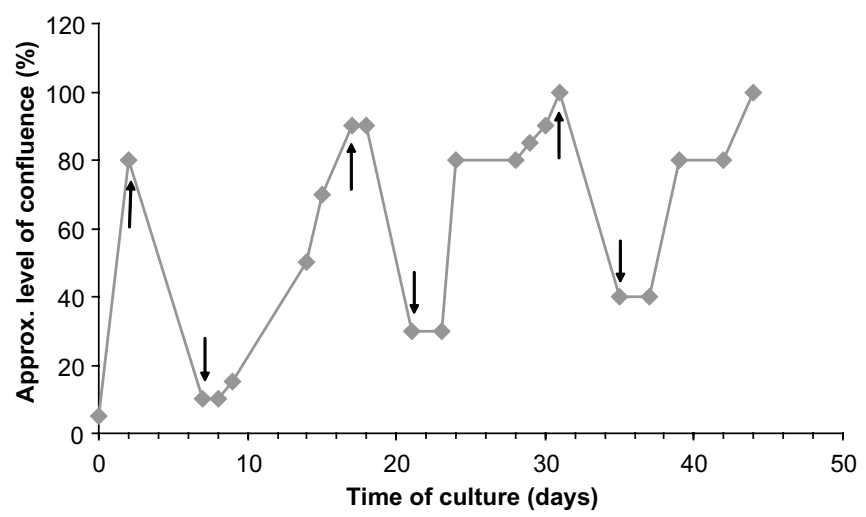

Fig. 2. Representative repeated exposure scheme. Exposure scheme of IHKE (lowOTA-subpopulation); $\uparrow$ start of exposure interval; $\downarrow$ end of exposure interval. The level of confluence was approximated during routine microscopy.

It was impossible to determine the doubling time for either HKCm OTB-subpopulation as it was higher than the time frame tested $(96 \mathrm{~h})$.

In contrast, $\mathrm{PKCm}$ subpopulations showed no changes in doubling time compared to untreated control cells. Interestingly, all IHKE subpopulations displayed a decreased population doubling time.

All PKCm and LLC-PK1 subpopulations showed an up to $50 \%$ reduction in cell number, when total cell number in the plateau phase was considered (Fig. 3B). This picture was not as consistent for $\mathrm{HKCm}$ cells, where the highOTA-subpopulation showed an increased total cell

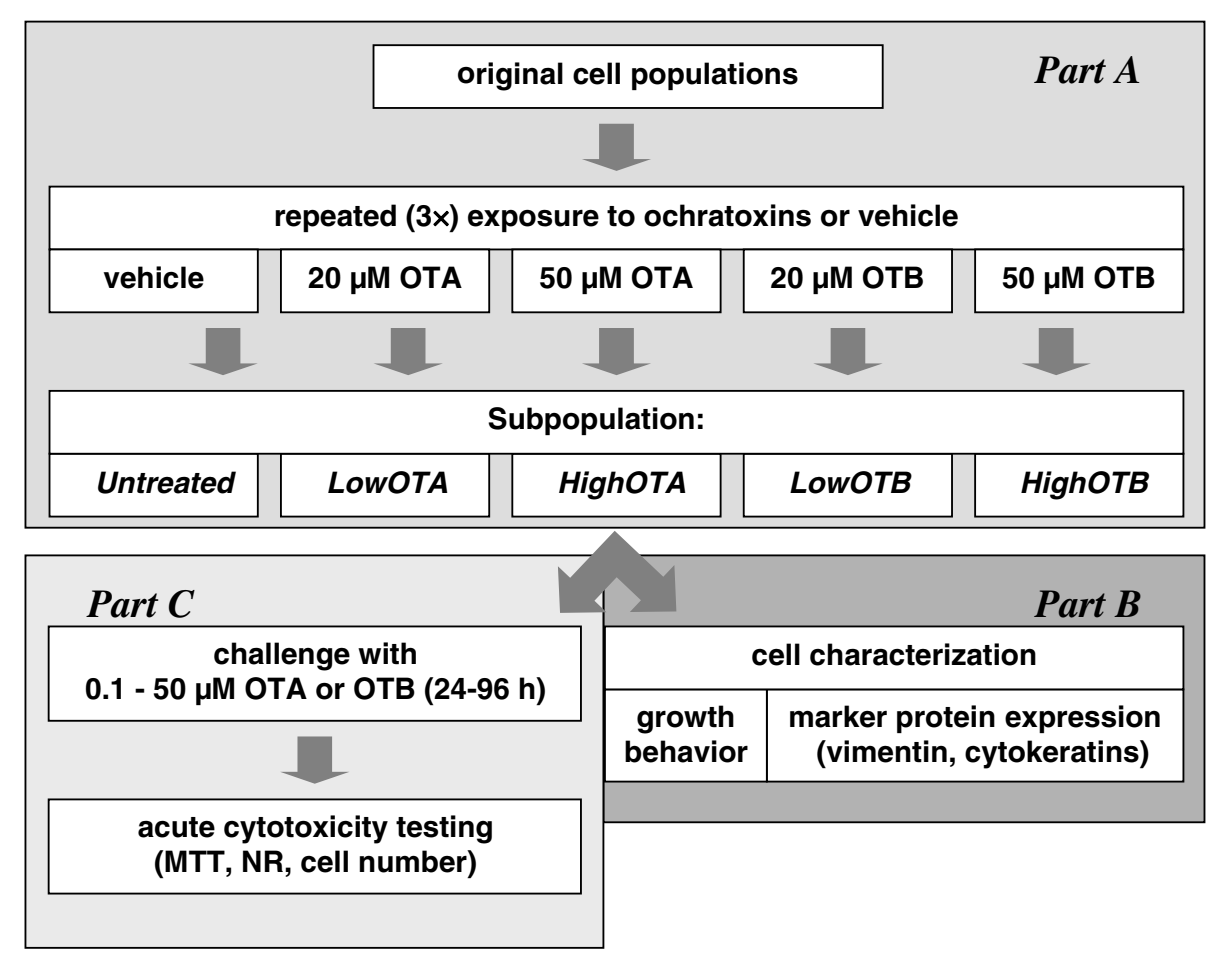

Fig. 1. Study design. Study part A: generation of cell subpopulations; study part B: characterization of cell subpopulations; study part C: determination of differential acute cytotoxic effects of ochratoxins in cell subpopulations. 

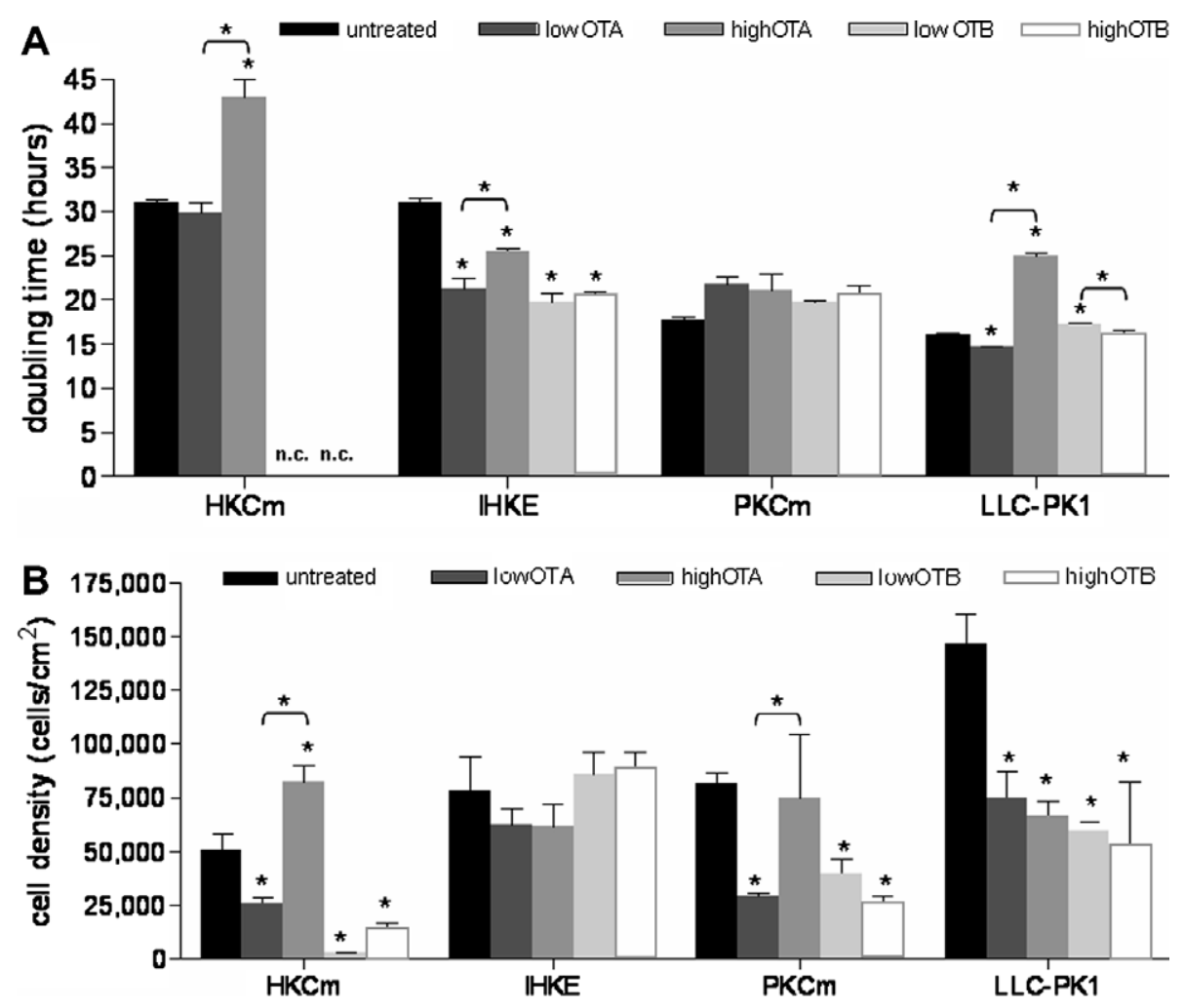

Fig. 3. Growth characteristics. A: Cell doubling times, B: cell densities in the plateau phase. Values represent the mean \pm SEM $(n=3)$. Significant differences compared to control or within groups were tested using a one-way ANOVA followed by Tukey's multiple comparison test and are indicated $\left({ }^{*} p<0.05\right)$. Cell subpopulations are named as outlined in Table 1. n.c., not computable due to doubling times surpassing the $96 \mathrm{~h}$ window of experiment.

number. All other $\mathrm{HKCm}$ subpopulations displayed a decreased cell number. In contrast, none of the IHKE subpopulations displayed any significant difference in the total number of cells in the plateau phase.

In summary, repeated exposure to ochratoxins resulted in altered growth behavior in all four cell types.

\subsection{Protein expression in cell subpopulations (study part B)}

The expression of two common cytoskeletal marker proteins for cellular origin, namely cytokeratin and vimentin, were chosen as endpoints. Representative immunodetection results are shown in Fig. 4. The monoclonal mouse anti-human cytokeratin antibody used can potentially detect up to eleven different cytokeratins of the basic and the acidic subfamily in the range of $40-67 \mathrm{kD}$ in a wide spectrum of human epithelial cells. This is dependent on the specific cell type and species of origin. In this study, a maximum of four specific bands could be visualized in human cells and only one in porcine cells (Fig. 4).

The HKCm subcultures highOTA, lowOTB and highOTB demonstrated a reduction in cytokeratin expression in comparison to their corresponding control. None of the other cell subpopulations displayed any difference in cytokeratin expression, which could be considered to be beyond normal protein loading and staining variance.

Vimentin expression was detected in the same manner in parallel. All control cells showed only very low expression

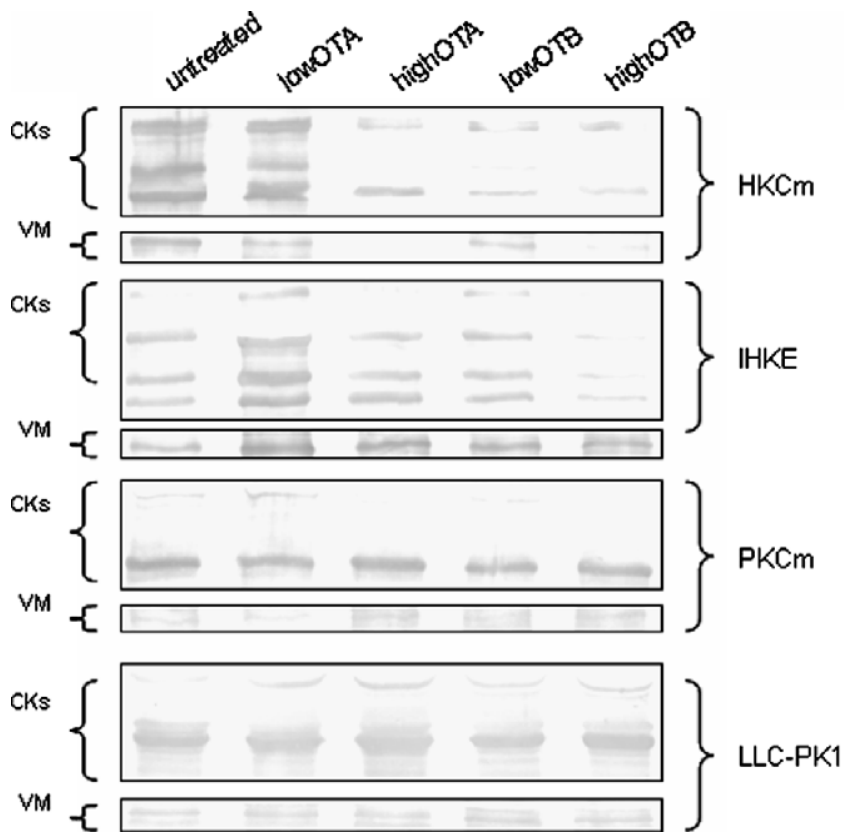

Fig. 4. Protein expression. Western blot analysis with DAB detection of cytokeratins (CKs) and vimentin (VM) expression in the cell subpopulations of $\mathrm{HKCm}$ ( $3 \mu \mathrm{g}$ total protein/lane), IHKE (4 $\mu \mathrm{g}$ total protein/lane), PKCm ( $6 \mu \mathrm{g}$ total protein/lane) and LLC-PK1 (10 $\mu \mathrm{g}$ total protein/lane). The monoclonal mouse anti-human cytokeratin antibody employed can potentially detect up to eleven different cytokeratins of the basic and the acidic subfamily in the range of $40-67 \mathrm{kD}$ in a wide spectrum of human epithelial cells. 
of vimentin. No increase could be detected in the ochratoxin subpopulations.

In summary, repeated exposure to ochratoxins resulted in altered cytokeratin expression in primary human cells only.

\subsection{Cytotoxic effects of acute challenge exposure to ochratoxins (study part C)}

Comparison of absolute $\mathrm{IC}_{50}$ values (Tables 2 and 3) for both toxins of the four control cell culture subpopulations showed species- and cell type-related differences in relative endpoint sensitivity. MTT reduction was the most sensitive endpoint for both human cell types (HKCm and IHKE), irrespective of the toxin used. In contrast, for porcine cells, cell number seemed to be a slightly more sensitive endpoint than either MTT reduction or NR uptake. Unless otherwise stated, in the following sections, the results of the control cells and the subpopulations are always described and compared using the most sensitive endpoint for the respective cell type.

OTA and OTB in control cells:

Primary porcine cells ( $\mathrm{PKCm})$ and the continuous porcine cell line (LLC-PK1) displayed similar sensitivities to OTA and OTB, however, PKCm seemed to be

Table 2

Results of cytotoxicity testing with OTA: comparison of integrated $\mathrm{IC}_{50}$ values $(24-96 \mathrm{~h}, \mu \mathrm{M})$

\begin{tabular}{|c|c|c|c|c|c|c|c|c|c|c|}
\hline \multirow{3}{*}{$\begin{array}{l}\text { Cell } \\
\text { cultures }\end{array}$} & \multirow[t]{3}{*}{ Endpoints } & \multicolumn{9}{|c|}{ Subpopulation } \\
\hline & & \multirow{2}{*}{$\frac{\text { Untreated }}{\mathrm{IC}_{50}}$} & \multicolumn{2}{|l|}{ lowOTA } & \multicolumn{2}{|l|}{ highOTA } & \multicolumn{2}{|l|}{ lowOTB } & \multicolumn{2}{|l|}{ highOTB } \\
\hline & & & $\mathrm{IC}_{50}$ & $\begin{array}{l}\text { Mean fold } \\
\text { change }\end{array}$ & $\mathrm{IC}_{50}$ & $\begin{array}{l}\text { Mean fold } \\
\text { change }\end{array}$ & $\mathrm{IC}_{50}$ & $\begin{array}{l}\text { Mean fold } \\
\text { change }\end{array}$ & $\mathrm{IC}_{50}$ & $\begin{array}{l}\text { Mean fold } \\
\text { change }\end{array}$ \\
\hline $\mathrm{HKCm}$ & $\begin{array}{l}\text { NR } \\
\text { MTT } \\
\text { CN }\end{array}$ & $\begin{array}{l}>50 \\
13.1 \pm 2.1 \\
>50\end{array}$ & $\begin{array}{l}>50 \\
21.8 \pm 10.8 \\
>50\end{array}$ & $\begin{aligned} \geqslant & 1.0 \\
& 1.7^{*} \\
\geqslant & 1.0\end{aligned}$ & $\begin{array}{l}>50 \\
17.0 \pm 6.9 \\
>50\end{array}$ & $\begin{aligned} \geqslant & 1.0 \\
& 1.3 \\
\geqslant & 1.0\end{aligned}$ & $\begin{array}{l}>50 \\
\geqslant 50.0 \\
>50\end{array}$ & $\begin{array}{l}\geqslant 1.0 \\
\geqslant 3.8 \\
\geqslant 1.0\end{array}$ & $\begin{array}{l}>50 \\
26.7 \pm 14.9 \\
>50\end{array}$ & $\begin{aligned} \geqslant & 1.0 \\
& 2.0^{*} \\
\geqslant & 1.0\end{aligned}$ \\
\hline $\mathrm{PKCm}$ & $\begin{array}{l}\text { NR } \\
\text { MTT } \\
\text { CN }\end{array}$ & $\begin{array}{r}13.4 \pm 5.0 \\
10.2 \pm 3.6 \\
8.1 \pm 3.2\end{array}$ & $\begin{array}{l}49.2 \pm 23.8 \\
17.5 \pm 6.4 \\
20.6 \pm 7.0\end{array}$ & $\begin{array}{l}3.7^{*} \\
1.7^{*} \\
2.5^{*}\end{array}$ & $\begin{array}{l}27.5 \pm 24.5 \\
16.0 \pm 3.9 \\
19.3 \pm 4.2\end{array}$ & $\begin{array}{l}2.1^{*} \\
1.6^{*} \\
2.4^{*}\end{array}$ & $\begin{aligned}> & 50 \\
& 11.2 \pm 3.2 \\
& 11.5 \pm 3.9\end{aligned}$ & $\begin{array}{r}>3.7 \\
1.1 \\
1.4\end{array}$ & $\begin{array}{l}40.1 \pm 21.5 \\
10.6 \pm 5.4 \\
17.7 \pm 6.1\end{array}$ & $\begin{array}{l}3.0^{*} \\
1.0 \\
2.2^{*}\end{array}$ \\
\hline LLC-PK1 & $\begin{array}{l}\text { NR } \\
\text { MTT } \\
\text { CN }\end{array}$ & $\begin{array}{l}24.1 \pm 10.9 \\
23.0 \pm 8.8 \\
13.9 \pm 2.6\end{array}$ & $\begin{array}{l}44.5 \pm 24.5 \\
24.0 \pm 14.6 \\
29.0 \pm 8.7\end{array}$ & $\begin{array}{l}1.8^{*} \\
1.0 \\
2.1^{*}\end{array}$ & $\begin{array}{l}>50 \\
19.8 \pm 10.9 \\
33.0 \pm 10.2\end{array}$ & $\begin{array}{c}>2.0 \\
0.9 \\
2.4^{*}\end{array}$ & $\begin{array}{l}18.4 \pm 5.6 \\
18.5 \pm 6.8 \\
14.4 \pm 5.0\end{array}$ & $\begin{array}{l}0.8 \\
0.8 \\
1.0\end{array}$ & $\begin{array}{l}>50 \\
22.7 \pm 10.2 \\
14.8 \pm 4.7\end{array}$ & $\begin{array}{r}>2.0 \\
1.0 \\
1.1\end{array}$ \\
\hline
\end{tabular}

Values represent integrated best-fit $\mathrm{IC}_{50}(24-96 \mathrm{~h}, \mu \mathrm{M})$ of OTA from non-linear regression $\pm 95 \%$ confidence intervals based on asymptotic standard errors. Significant differences compared to control are indicated $\left({ }^{*} p<0.05\right)$. $\geqslant$, values are at least as high as control, but higher than the tested concentration range (i.e. $>50 \mu \mathrm{M}$ ); > values are higher than control values, but higher than the tested concentration range.

Table 3

Results of cytotoxicity testing with OTB: comparison of integrated $\mathrm{IC}_{50}$ values $(24-96 \mathrm{~h}, \mu \mathrm{M})$

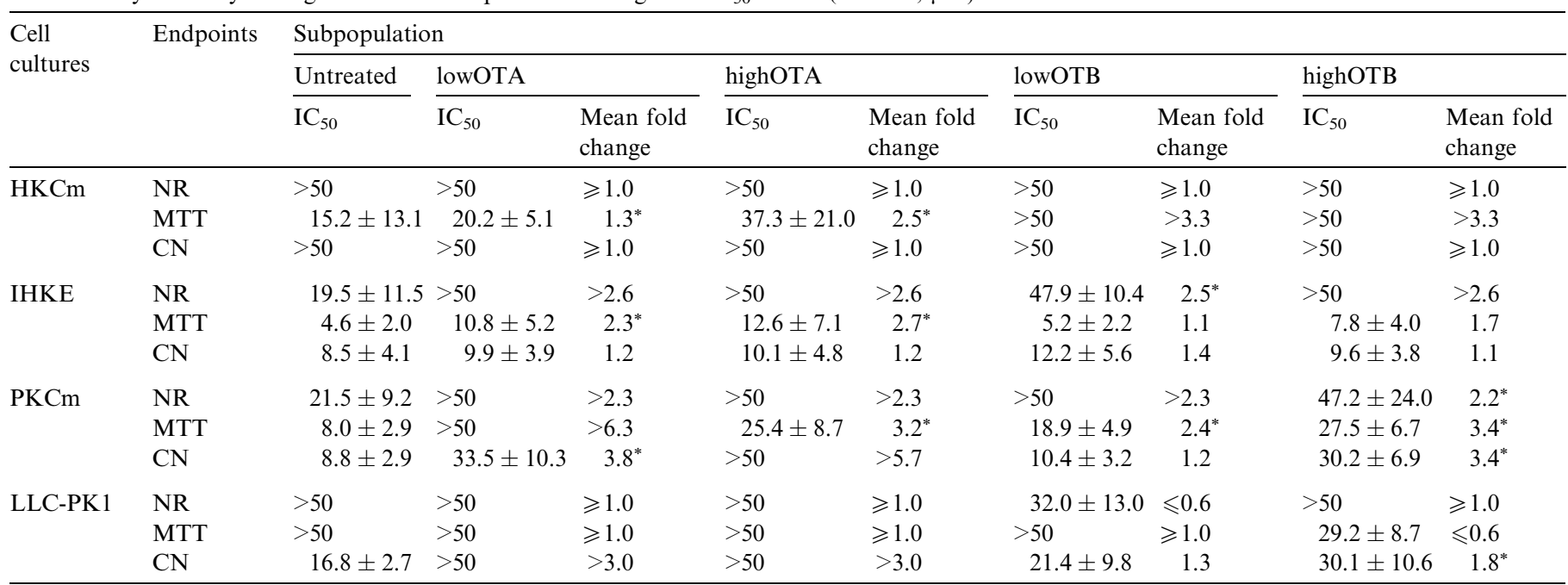

Values represent integrated best-fit $\mathrm{IC}_{50}(24-96 \mathrm{~h}, \mu \mathrm{M})$ of OTA from non-linear regression $\pm 95 \%$ confidence intervals based on asymptotic standard errors. Significant differences compared to control are indicated $\left({ }^{*} p<0.05\right)$. $\geqslant$, values are at least as high as control, but higher than the tested concentration range (i.e. $>50 \mu \mathrm{M}$ ); $>$, values are higher than control values, but higher than the tested concentration range. 
slightly more sensitive towards both ochratoxins than LLC-PK1 cells, when absolute $\mathrm{IC}_{50}$ values for OTA and OTB were compared (Tables 2 and 3). In contrast, primary human cells $(\mathrm{HKCm})$ displayed a lower sensitivity than the corresponding continual cell line IHKE, but also a similar cytotoxic response to both toxins.

When the most sensitive endpoints are compared, no distinct species differences in cytotoxic effects of OTA and OTB were apparent.

Of the four cell types tested, the IHKE cell line seemed to be the most sensitive cell type to ochratoxin exposure.

\section{OTA in cell subpopulations:}

The effects of OTA exposure on the various cell subpopulations compared to their corresponding control cell cultures are shown in Table 2.

HKCm-subpopulations displayed a reduced sensitivity towards OTA-mediated cytotoxicity compared to their corresponding control. In contrast, none of the IHKEsubpopulations showed any significant alteration in sensitivity towards OTA cytotoxicity.

PKCm subpopulations (lowOTA, highOTA and highOTB) also displayed a lower sensitivity to OTA exposure, whereas no altered effect could be observed in the PKCm lowOTB-subpopulation.

Both LLC-PK1 OTA-subpopulations also displayed a decreased sensitivity to OTA exposure, whereas the sensitivity of both OTB-subpopulations was unaltered.

\section{OTB in cell subpopulations:}

Table 3 shows the effects of OTB exposure on the various cell subpopulations in comparison with their corresponding control cell cultures.

All subpopulations of $\mathrm{HKCm}$ cells displayed a decreased sensitivity towards OTB cytotoxicity. Both IHKE OTAsubpopulations displayed a comparable decrease, whereas no significant effects were seen in either of the OTB-subpopulations.

All PKCm cell subpopulations showed an even more notable decrease in sensitivity (up to 6.3-fold) to OTBchallenge. LLC-PK1 cells generally showed similar trends, however, only few data were statistically significant.

Thus, although some contradictory observations were apparent, repeated exposure to OTA or OTB generally resulted in a decreased sensitivity towards subsequent OTA- and OTB-mediated cytotoxicity in human and porcine cells. This effect was most prominent in primary porcine cells.

\section{Discussion}

In order to generate ochratoxin-derived cell subpopulations as a model of repeated ochratoxin exposure, it was first necessary to induce renal cell regeneration processes due to cell loss. Long-term or extended in vitro studies in general are subject to the problem of limited life span of primary cells. In order to overcome this problem, acutely toxic concentrations of OTA and OTB had to be used, although such high concentrations are unlikely to occur in the kidney in vivo under normal circumstances. Preliminary experiments indicated that the repeated exposure to either $20 \mu \mathrm{M}$ or $50 \mu \mathrm{M}$ OTA and OTB at approximately $90 \%$ confluency yields expandable cell subpopulations for subsequent analysis. This exposure regime resulted in five subpopulations for each of the four cell types, which could be used as a model in the presented study.

At first, these cell subpopulations were subjected to rudimentary characterization. The investigation of cell growth behavior demonstrated that the lowOTA-LLC-PK1 subpopulation and all IHKE cell subpopulations responded with higher cellular proliferation rates. All other cell subpopulations displayed slower or in some cases unaltered growth rates. The total cell number at confluence was decreased in most cell subpopulations, only IHKE cells did not show any alteration. These observations may be explained by the fact, that this cell line is originally a toxin-derived cell subpopulation $\left(\mathrm{NiSO}_{4}\right.$ clonogenicity) (Tveito et al., 1989), which probably represents a different control cell type compared to the other three cell types investigated. Therefore, caution is advised in the interpretation of results obtained using this cell type.

The investigated expression of marker proteins showed only effects in all four human primary cell subpopulations, where the cytokeratin expression seemed to be altered. All other cell subpopulations showed no changes. No increase in vimentin expression was detected in any cell type.

A comparison between the three different cytotoxicity endpoints used in this study demonstrated that not all endpoints provide similar results. The four investigated cell types showed a distinct species- and cell type-related endpoint-sensitivity. In both human cell types, the MTT reduction assay was the most sensitive endpoint, whereas total cell number seemed to be a slightly more sensitive endpoint in both porcine cell types. These results suggest that the endpoint for cytotoxicity testing in renal cells should be chosen according to their most sensitive behavior, which may differ between cell cultures of various sources.

Considering the data from the most sensitive endpoints, there is a clear decrease in cytotoxic response to OTA in all OTA-subpopulations and to OTB in all OTB-subpopulations, with the exception of IHKE cells, where sensitivity was unaltered.

No observable cytotoxicity difference between OTA and OTB was found in all control cell cultures and endpoints tested. At first, this appeared to stand in contrast to literature data including our own earlier findings (Dietrich et al., 2001; Heussner et al., 2006; O'Brien et al., 2001). The latter data showed a higher toxicity of OTA compared to that of OTB in various renal cell types, however these data always originated from single time-point short-term investigations. In the current study, an extended integrated time-interval of $96 \mathrm{~h}$ was investigated, obviously leading to a different outcome. More recent data from other investigators have 
also described only minor cytotoxicity differences between OTA and OTB in LLC-PK1 cells when short-term effects are investigated, but no differences when higher concentrations or longer exposure times were employed (Mally et al., 2005).

Recently, Bruene and co-workers followed a similar repeated exposure approach of OTA (20 weeks) using HEK293 and NRK-52E cells. Here, also cell-type specific effects were detected. HEK293 cells displayed a transiently decreased sensitivity towards OTA combined with an increase in cell proliferation rates measured as an increased S-phase cell fraction. No such effects were detected in NRK-52E cells (B. Bruene, personal communication).

Thus it appears that repeated exposure to ochratoxins causes alterations in fundamental cellular characteristics and properties. If this is indeed associated with a real fibroblastic phenotype is unclear, however, the dedifferentiation of renal epithelial cells into fibroblast-like cells (and vice versa) has previously been described (Strutz et al., 1996). In rats, this transdifferentiation is accompanied by loss of cellular polarity, tight junctions, elongation, detachment and separation from neighboring cells ( $\mathrm{Ng}$ et al., 1998). To date little is known about the mechanisms of transdifferentiation, however it seems often to be associated with changes in intermediary filaments, i.e. keratin expression is lost and vimentin appears, and collagen secretion is enhanced. Transdifferentiation has furthermore been discussed in relation to BEN (Markovic-Lipkovski, 2002). Indeed, Sauvant and colleagues hypothesized epithelialto-mesenchymal transition because of OTA-induced enhancement of collagen secrection in OK cells and primary human proximal tubular epithelial cells (RPTECs) (Sauvant et al., 2005).

However, contrary to expectations based on the above publications, no overt morphological changes were seen in any of the cell subpopulations tested in this study. Moreover, no alterations in the expression of intermediary filaments (cytokeratins and vimentin) in PKCm, IHKE and LLC-PK1 cells, with the exception of lower cytokeratin expression in highOTA, lowOTB and highOTB HKCm subpopulations were observed. Whether or not the latter observations result from concentration effects or substancespecific mechanisms as previously suggested (O'Brien et al., 2001), cannot be derived from the current data.

In summary, the hypothesis of alteration of normal renal epithelial cells after repeated exposure to ochratoxins, detectable as alterations in parameters, e.g. morphology, growth rate and susceptibility to acutely cytotoxic concentrations of ochratoxins, was corroborated with the data presented in this study. These observations may be explained by the phenomenon of epithelial-to-mesenchymal transition (EMT), a selection for less ochratoxin-sensitive cells, or an adaptive behavior of the cells during repeated exposure.

Further investigations, including the introduction of model substances for cellular transformation (for example cyclosporine A, TGF- $\beta 1, \mathrm{H}_{2} \mathrm{O}_{2}$ ) (McMorrow et al., 2005;
Rhyu et al., 2005; Zhuang et al., 2005) and additional marker proteins (i.e. $\alpha$-smooth muscle actin, cadherins, collagens, matrix metalloproteinases, etc.), recently shown to be involved in ochratoxin A-induced renal cortex fibrosis and EMT in vivo (Gagliano et al., 2005), are needed to elucidate the underlying mechanism.

The extrapolation of the in vitro data to a possible in vivo situation also suggests that ochratoxin-dependent increased cellular regeneration time may be an important factor contributing to the observed renal fibrosis in ochratoxin-exposed pigs and possibly also in humans. Indeed, slowed epithelial cell regeneration could explain earlier findings that ochrotoxins can also induce invasion of the renal interstitia by fibroblasts as a measure of maintaining structural, but not functional, integrity of the kidney.

Whether the observed alterations are of stable and/or phenotypic or of temporary adaptive nature, should be investigated in the future to allow further insight into long-term ochratoxin effects.

\section{Acknowledgements}

We would like to thank M.E. Stack, US FDA, Washington, DC, and S. Mollerup, National Institute of Occupational Health (STAMI), Oslo, Norway, for kindly providing highly purified ochratoxins (OTA, OTB) and IHKE cells, respectively.

We also acknowledge the excellent collaboration with Prof. Dr. R. Thiel and his colleagues (Klinikum Konstanz).

The authors also gratefully acknowledge C. Zinssmeister, S. Iskra, C. Rockel and T. Lampertsdoerfer for their excellent assistance with the cytotoxicity experiments.

\section{References}

Dekant, W., Schilter, B., Mantle, P., Pfohl-Leszkowicz, A., Dogliotti, E., Mosesso, P., Honegger, P., 2005. Mechanisms of ochratoxin A induced carcinogenicity as a basis for an improved risk assessment. Report number QLK1-2001-01614. The European Commission Community Research: Quality of Life and management of Living Resources.

Dietrich, D.R., O’Brien, E., Stack, M.E., Heussner, A.H., 2001. Speciesand sex-specific renal cytotoxicity of ochratoxin $\mathrm{A}$ and $\mathrm{B}$ in vitro. Experimental and Toxicologic Pathology 53, 215-225.

Eckert, W.A., Kartenbeck, J., 1997. Proteine, Standardmethoden der Molekularbiologie und Zellbiologie. Springer, Berlin.

Gagliano, N., Torri, C., Donetti, E., Grizzi, F., Costa, F., Bertelli, A.A., Migliori, M., Filippi, C., Bedoni, M., Panichi, V., Giovannini, L., Gioia, M., 2005. Ochratoxin A-induced renal cortex fibrosis and epithelial-to-mesenchymal transition: molecular mechanisms of ochratoxin A-injury and potential effects of red wine. Molecular Medicine 11 (1-12), 30-38.

Grotegut, S., O’Brien, E., Stack, M.E., Hochberg, K., Dietrich, D.R., 2001. Differential in vitro cytotoxicity of ochratoxin A in renal proximal epithelial cells and renal fibroblasts. Toxicological Sciences 60,419 .

Heussner, A.H., O’Brien, E., Stack, M.E., Thiel, R., Dietrich, D.R., 2002. Cytotoxicity of OTA and OTB in human and porcine renal cells after repeated exposure. Toxicological Sciences 66, 398.

Heussner, A.H., Dietrich, D.R., O’Brien, E., 2006. In vitro investigation of individual and combined cytotoxic effects of ochratoxin A and other selected mycotoxins on renal cells. Toxicology in Vitro 20, 332-341. 
Mally, A., Keim-Heusler, H., Amberg, A., Kurz, M., Zepnik, H., Mantle, P., Volkel, W., Hard, G.C., Dekant, W., 2005. Biotransformation and nephrotoxicity of ochratoxin $\mathrm{B}$ in rats. Toxicology and Applied Pharmacology 206, 43-53.

Markovic-Lipkovski, J., 2002. Tubuloepithelial-myofibroblast transdifferentiation - possible pathogenic mechanism of interstitial fibrosis in Balkan Endemic Nephropathy. Facta Universitatis - Medicine and Biology 9, 79-81.

McMorrow, T., Gaffney, M.M., Slattery, C., Campbell, E., Ryan, M.P., 2005. Cyclosporine A induced epithelial-mesenchymal transition in human renal proximal tubular epithelial cells. Nephrology, Dialysis, Transplantation 20 (10), 2215-2225.

Ng, Y.Y., Huang, T.P., Yang, W.C., Chen, Z.P., Yang, A.H., Mu, W., Nikolic-Paterson, D.J., Atkins, R.C., Lan, H.Y., 1998. Tubular epithelial-myofibroblast transdifferentiation in progressive tubulointerstitial fibrosis in 5/6 nephrectomized rats. Kidney International 54, 864-876.

Nony, P.A., Schnellmann, R.G., 2003. Mechanisms of renal cell repair and regeneration after acute renal failure. The Journal of Pharmacology and Experimental Therapeutics 304, 905-912.

O'Brien, E., Dietrich, D.R., 2005. Ochratoxin A: the continuing enigma. Critical Reviews in Toxicology 35, 33-60.

O'Brien, E., Heussner, A.H., Dietrich, D.R., 2001. Species-, sex-, and cell type-specific effects of ochratoxin A and B. Toxicological Sciences 63, $256-264$.

Pfohl-Leszkowicz, A., Petkova-Bocharova, T., Chernozemsky, I.N., Castegnaro, M., 2002. Balkan endemic nephropathy and associated urinary tract tumours: a review on aetiological causes and the potential role of macotoxins. Food Additives and Contaminants 19, 282-302.

Rásonyi, T., Schlatter, J., Dietrich, D.R., 1999. The role of $\alpha 2$ u-globulin in ochratoxin A induced renal toxicity and tumors in F344 rats. Toxicology Letters 104, 83-92.

Rhyu, D.Y., Yang, Y., Ha, H., Lee, G.T., Song, J.S., Uh, S.T., Lee, H.B., 2005. Role of reactive oxygen species in TGF-betal-induced mitogen- activated protein kinase activation and epithelial-mesenchymal transition in renal tubular epithelial cells. Journal of the American Society of Nephrology 16, 667-675.

Sauvant, C., Holzinger, H., Mildenberger, S., Gekle, M., 2005. Exposure to nephrotoxic Ochratoxin A enhances collagen secretion in human renal proximal tubular cells. Molecular Nutrition and Food Research $49,31-37$.

Speijers, G.J.A., van Egmond, H.P., 1993. Worldwide ochratoxin A levels in food and feeds. In: Creppy, E.E., Castegnaro, M., Dirheimer, G. (Eds.), Human Ochratoxicosis and its Pathologies. John Libbey Eurotext Ltd., Montrouge, France, pp. 85-100.

Stefanovic, V., Toncheva, D., Atanasova, S., Polenakovic, M., 2006. Etiology of Balkan Endemic Nephropathy and associated urothelial cancer. American Journal of Nephrology 26, 1-11.

Stoev, S.D., 1998. The role of ochratoxin A as a possible cause of Balkan Endemic Nephropathy and its risk evaluation. Veterinary and Human Toxicology 40, 352-360.

Strutz, F., Muller, G.A., Neilson, E.G., 1996. Transdifferentiation: a new angle on renal fibrosis. Experimental Nephrology 4, 267-270.

Studer-Rohr, I., 1995. Ochratoxin A in humans: exposure, kinetics and risk assessment, Dissertation. ETH Zürich (Switzerland).

Tatu, C.A., Orem, W.H., Finkelman, R.B., Feder, G.L., 1998. The etiology of Balkan endemic nephropathy: still more questions than answers. Environmental Health Perspectives 106, 689-700.

Tveito, G., Hansteen, I.-L., Dalen, H., Haugen, A., 1989. Immortalization of normal human kidney epithelial cells by nickel(II). Cancer Research 49, 1829-1835.

van Kooten, C., Lam, S., Daha, M.R., 2001. Isolation, culture, characterization and use of human renal tubular epithelial cells. Journal of Nephrology 14, 204-210.

Zhuang, S., Yan, Y., Han, J., Schnellmann, R.G., 2005. p38 kinasemediated transactivation of the epidermal growth factor receptor is required for dedifferentiation of renal epithelial cells after oxidant injury. Journal of Biological Chemistry 280 (22), 21036-21042. 